\title{
Correlation and Path Coefficient Analysis of Yield and Yield Associated Traits in Small Onion
}

\author{
M. Visalakshi ${ }^{1}$, C. Porpavai ${ }^{2}$ and M. Pandiyan ${ }^{1}$ \\ ${ }^{1}$ AC \& RI, Eachangkottai, Tamil Nadu Agricultural University, Thanjavur, Tamil Nadu, India \\ ${ }^{2}$ SWMRI, TNAU, Kattuthottam, Thanjavur, Tamil Nadu, India \\ *Corresponding author
}

\begin{tabular}{|l|}
\hline Ke y w o r d s \\
Small onion, \\
Phenotypic and \\
genotypic \\
correlation, Path \\
coefficient
\end{tabular}

\section{Keywords}

mall onion, genotypic correlation, Path 10 July 2018

\section{A B S T R A C T}

Genotypes of small onion were evaluated during 2014-2016 to determine the genotypic and phenotypic correlation along with their direct and indirect effects for bulb yield through path coefficient analysis in small onion. The experiment was conducted in a randomized block design (RBD) in two seasons with three replications at Soil and Water Management Research Institute, Kattuthottam, Thanjavur. The experiment result revealed that in most of the cases the genotypic correlation is higher than the corresponding phenotypic correlation values. This suggests that there inherit a strong relationship between the characters. In the present study, during summer season the bulb yield per hectare was positively and significantly associated with plant height at bulb formation stage (0.903), number of leaves at vegetative stage (0.813), neck thickness (0.886), neck diameter (0.868), equatorial diameter of bulb (0.91) and bulb weight (846). Higher number of leaves at vegetative stage is positively correlated and significant at polar diameter and equatorial diameter of bulb. Yield associating characters like neck thickness, neck diameter and polar diameter were also highly significant and positively correlated. During Kuruvai season, Bulb yield per hectare is highly significant and positively correlated with plant height at bulb formation stage (0.926) followed by bulb weight $(0.96)$, neck thickness (0.889), equatorial diameter of bulb (0.873), polar diameter of bulb (0.852) and number of leaves at vegetative stage (0.834). Neck thickness expressed a highly significant and positive correlation co-efficient with polar and equatorial diameter $\&$ bulb weight. Polar and diameter is interrelated and positively correlated with equatorial diameter and bulb weight. Path coefficient of different characters contributing towards bulb yield during summer and kuruvai season bulb weight had the positive direct effect followed by equatorial diameter of the bulb, neck thickness, plant height at bulb formation stage and bulb filled stage and number of leaves at bulb formations stage. The improvement in marketable bulb yield per plant will be efficient, if the selection is based on bulb weight, neck thickness, plant height at bulb filled and bulb formation stage, polar diameter and equatorial diameter of bulb. 


\section{Introduction}

Onion is an important bulb crop belongs to the family Alliaceae. It is grown for food, religious purpose, spices and condiments since early times. Bulb yield in onion is a complex character controlled by many factors. In order to evaluate the promising genotypes with high yield it is essential to know the associations among different traits especially with bulb yield. Therefore selection for desirable genotypes should be based on bulb yield and also other yield attributes which influences the yield. The correlation and path analysis are usually taken up to measure the relative magnitude and direction of each independent variable on a dependent variable like bulb yield. Som Pal Baliyan (2014) evaluated for six varieties of onion adaptability to the climatic conditions in Botswana. Crops performs in a different way under varied climatic conditions and varieties of same species cultivated in the same environments gives different yields as the potential of the crop depends on the interaction of genetic makeup and environment (Jilani and Ghafoor, 2003; Kimani et al., 1993). The present investigation was therefore planned to estimate the extent of association among yield and yield attributes in small onion types for 11 characters in the Cauvery Delta Region.

\section{Materials and Methods}

The present investigation on correlation and path analysis in diverse onion was conducted at Soil and Water Management Research Institute, Kattuthottam, Thanjavur during 2014 - 2016. The experiment materials of the present investigation was comprised of seven genotypes of small onion viz., $\mathrm{Co} 4, \mathrm{CO}(\mathrm{On}) 5$, Arka Bindu, Agri Found Rose, Perambalur Local, Cuddalore Local and Ottanchatram Local and experiment is conducted in Randomized Block Design with three replications to estimate the genetic variability, association and path analysis. Observations were recorded on the basis of five random competitive plants selected from each genotype separately for quantitative and qualitative parameters were evaluated as per the standard procedure. The main objectives were to estimate the genetic variability, correlation and path co-efficient analysis between yield and its attributing characters to identify better performing genotypes in small onion. The correlation co-efficient were calculated in all possible combinations taking all the characters into consideration at genotypic, phenotypic and environmental levels. The mean values of plants were utilized for estimation of genotypic correlation coefficient as per the method suggested by Johnson et al., (1955) whereas path coefficient analysis was worked out by the methods used by Dewey and Lu (1959) to find out the relationship between yield and yield attributes.

\section{Results and Discussion}

\section{Correlation coefficient analysis}

The genotypic correlation coefficients were higher as compared to phenotypic correlation coefficient in most of the cases (Table 1). This indicates greater contribution of genotypic factor in the development of the character associations. The findings are in agreement to Raghuwanshi et al., (2016) and Hosamani et al., (2010). In the present study, during summer season the bulb yield per hectare was positively and significantly associated with plant height at bulb formation stage (0.903), number of leaves at vegetative stage (0.813), neck thickness (0.886), neck diameter (0.868), equatorial diameter of bulb (0.91) and bulb weight (846). The phenotypic value is lessened by the significant environment interaction. During kuruvai season, the magnitude of genotypic correlation was higher than the phenotypic correlation for most of the traits that indicated inherent association 
between various characters (Table 2). Bulb yield per hectare recorded is highly significant and positive correlation with plant height at bulb formation stage (0.926) followed by bulb weight (0.96), neck thickness (0.889), equatorial diameter of bulb (0.873), polar diameter of bulb (0.852) and number of leaves at vegetative stage (0.834) indicating that these characters are the primary yield determinants in onion and can be improved through direct selection. These findings corroborate the earlier findings of Hosamani et al., (2010); Dhotre et al., (2010); Awale et al., (2011); Saini and Maurya (2014) for equatorial diameter; Awale et al., (2011) and Saini and Maurya (2014) for polar diameter; Dhotre et al., (2010), Awale et al., (2011); Saini and Maurya (2014) for neck thickness; Hayder et al., (2007) and Saini and Maurya (2014) for plant height.

While considering the interrelationship among the bulb yield contributing parameters, plant height at bulb filled stage is positively correlated with neck thickness (0.988), neck diameter (0.983), polar diameter of bulb (0.812), equatorial diameter of bulb (0.945) and bulb weight (0.882) and negatively associated with days for harvesting. Higher number of leaves at vegetative stage is positively correlated and significant at polar diameter and equatorial diameter of bulb. Yield associating characters like neck thickness, neck diameter and polar diameter were also highly significant and positively correlated. Therefore to improve the bulb yield in onion the above said associated characters should be given due consideration during the selection of genotypes for breeding. While in kuruvai season, plant height at bulb formation stage showed significant and positive correlation with number of leaves at vegetative and bulb formation stage, neck thickness, polar and equatorial diameter of the bulb and weight of the bulb. Neck thickness expressed a highly significant and positive correlation co-efficient with polar and equatorial diameter and bulb weight. Polar diameter is interrelated and positively correlated with equatorial diameter and bulb weight. The findings are in agreement to Raghuwanshi et al., (2016); Hosamani et al., (2010); Awale et al., (2011); Dhall and Brar (2013) and Saini and Maurya (2014). Equatorial diameter of the bulb was negatively associated with days for harvesting but positively correlated with bulb weight. The findings corroborate the earlier findings of Raghuwanshi et al., (2016); Hosamani et al., (2010); Awale et al., (2011) and Saini and Maurya (2014). This indicates that the associating parameters like neck thickness, polar and equatorial diameter, bulb weigh can be considered during the varietal selection.

\section{Path co-efficient analysis}

Path coefficient of different characters contributing towards bulb yield during summer and Kuruvai season revealed that bulb weight had the positive direct effect followed by equatorial diameter of the bulb, neck thickness, plant height at bulb formation stage and bulb filled stage and number of leaves at bulb formations stage (Table 3). Days for harvesting have negative direct effect with the bulb yield. The parameters such as polar diameter of the bulb, bulb weight, plant height at bulb formation and bulb filled stage have the positive indirect effects towards the yield contributing characters like bulb yield. The results are in propinquity with Aliya et al., (2007); Dhotre et al., (2010) and Hosamani et al., (2010) for polar diameter, Sharma et al., (2015) for plant height, Barad et al., (2012) for bulb weight, polar, equatorial and Sharma et al., (2015) for number of leaves per plant. Number of leaves, equatorial diameter and days for harvesting has expressed negative indirect effects. 
Table.1 Estimates of genetic and phenotypic correlation coefficient analysis among yield and its contributing traits in small onion during summer season

\begin{tabular}{|c|c|c|c|c|c|c|c|c|c|c|c|c|}
\hline Character & & 1 & 2 & 3 & 4 & 5 & 6 & 7 & 8 & 9 & 10 & 11 \\
\hline \multirow[t]{2}{*}{1} & $\mathbf{P}$ & 1 & 0.661 & $0.824 * *$ & $0.896 * *$ & 0.517 & 0.567 & $0.839 * *$ & $0.765 * *$ & $-0.812 * *$ & $0.871 * *$ & 0.595 \\
\hline & G & 1 & 0.7 & $0.835 * *$ & $0.899 * *$ & 0.535 & 0.589 & $0.852 * *$ & $0.785 * *$ & -0.312 & $0.882 * *$ & 0.562 \\
\hline \multirow[t]{2}{*}{2} & $\mathbf{P}$ & & 1 & 0.659 & 0.557 & $0.988 * *$ & $0.983 * *$ & $0.812 * *$ & $0.945^{* *}$ & -0.347 & $0.946 * *$ & $0.903^{* *}$ \\
\hline & G & & 1 & 0.682 & 0.586 & $0.962 * *$ & $0.965 * *$ & $0.825 * *$ & $0.945 * *$ & 0.051 & $0.947 * *$ & $0.831 * *$ \\
\hline \multirow[t]{2}{*}{3} & $\mathbf{P}$ & & & 1 & $0.789 * *$ & 0.596 & 0.639 & $0.842 * *$ & $0.809 * *$ & -0.58 & $0.793 * *$ & $0.813 * *$ \\
\hline & G & & & 1 & $0.8 * *$ & 0.61 & 0.654 & $0.852 * *$ & $0.821 * *$ & -0.223 & $0.806^{* *}$ & $0.787 * *$ \\
\hline \multirow[t]{2}{*}{4} & $\mathbf{P}$ & & & & 1 & 0.415 & 0.459 & 0.694 & $0.743 * *$ & $-0.994 * *$ & $0.745^{* *}$ & 0.562 \\
\hline & G & & & & 1 & 0.435 & 0.482 & 0.711 & $0.757 * *$ & -0.52 & $0.759 * *$ & 0.546 \\
\hline \multirow[t]{2}{*}{5} & $\mathbf{P}$ & & & & & 1 & $0.983 * *$ & $0.736^{*}$ & $0.898 * *$ & -0.094 & $0.867 * *$ & $0.9 * *$ \\
\hline & $\mathbf{G}$ & & & & & 1 & $0.983 * *$ & $0.743 * *$ & $0.896 * *$ & 0.049 & $0.866 * *$ & $0.886^{* *}$ \\
\hline \multirow[t]{2}{*}{6} & $\mathbf{P}$ & & & & & & 1 & $0.825 * *$ & $0.923 * *$ & -0.068 & $0.886 * *$ & $0.868 * *$ \\
\hline & G & & & & & & 1 & $0.831 * *$ & $0.923 * *$ & 0.092 & $0.888 * *$ & $0.849 * *$ \\
\hline \multirow[t]{2}{*}{7} & $\mathbf{P}$ & & & & & & & 1 & $0.868 * *$ & -0.266 & $0.894 * *$ & 0.707 \\
\hline & G & & & & & & & 1 & $0.878 * *$ & 0.012 & $0.902 * *$ & 0.679 \\
\hline \multirow[t]{2}{*}{8} & $\mathbf{P}$ & & & & & & & & 1 & -0.516 & $0.953 * *$ & $0.91 * *$ \\
\hline & G & & & & & & & & 1 & -0.149 & $0.956 * *$ & $0.872 * *$ \\
\hline \multirow[t]{2}{*}{9} & $\mathbf{P}$ & & & & & & & & & 1 & -0.537 & -0.312 \\
\hline & $\mathbf{G}$ & & & & & & & & & 1 & -0.153 & -0.223 \\
\hline \multirow[t]{2}{*}{10} & $\mathbf{P}$ & & & & & & & & & & 1 & $0.846^{* *}$ \\
\hline & G & & & & & & & & & & 1 & $0.808 * *$ \\
\hline \multirow[t]{2}{*}{11} & & & & & & & & & & & & 1 \\
\hline & \multicolumn{7}{|c|}{$\begin{array}{l}*, * * \text { - significant at } 5 \% \text { and } 1 \% \text { levels respectively } \\
1 \text { - Plant height at bulb formation stage } \\
2 \text { - Plant height at bulb filled stage } \\
3 \text { - Number of leaves at vegetative stage } \\
4 \text { - Number of leaves at bulb filled stage } \\
5 \text { - Neck thickness }\end{array}$} & \multicolumn{5}{|c|}{$\begin{array}{l}6 \text { - Neck diameter } \\
7 \text { - Polar diameter of bulb } \\
8 \text { - Equatorial diameter of bulb } \\
9 \text { - Days for harvesting } \\
10 \text { - Bulb weight } \\
11 \text { - Bulb yield per ha }\end{array}$} \\
\hline
\end{tabular}


Table 2 Estimates of genetic and phenotypic correlation coefficient analysis among yield and its contributing traits in small onion during Kuruvai season

\begin{tabular}{|c|c|c|c|c|c|c|c|c|c|c|c|c|}
\hline Characters & & 1 & 2 & 3 & 4 & 5 & 6 & 7 & 8 & 9 & 10 & 11 \\
\hline \multirow[t]{2}{*}{1} & $\mathbf{P}$ & 1 & $0.862 * *$ & $0.972 * *$ & $0.929 * *$ & $0.913 * *$ & 0.433 & $0.911 * *$ & $0.932 * *$ & $-0.934 * *$ & $0.961 * *$ & $0.926^{* *}$ \\
\hline & G & 1 & $0.886 *$ & $0.977 * *$ & $0.927 * *$ & $0.89 * *$ & 0.451 & $0.905 * *$ & $0.93 * *$ & -0.323 & $0.961 * *$ & $0.831 * *$ \\
\hline \multirow[t]{2}{*}{2} & $\mathbf{P}$ & & 1 & $0.937 * *$ & $0.902 * *$ & $0.87 * *$ & 0.694 & $0.888 * *$ & $0.75^{* *}$ & $-0.998^{*}$ & $0.788 * *$ & 0.708 \\
\hline & $\mathbf{G}$ & & 1 & $0.945^{* *}$ & $0.956^{* *}$ & $0.813 * *$ & 0.653 & $0.855^{* *}$ & $0.756^{* *}$ & -0.276 & $0.8 * *$ & 0.582 \\
\hline \multirow[t]{2}{*}{3} & $\mathbf{P}$ & & & 1 & $0.99 * *$ & $0.9 * *$ & 0.557 & $0.922 * *$ & $0.91 * *$ & $-0.954 * *$ & $0.917 * *$ & $0.834 * *$ \\
\hline & $\mathbf{G}$ & & & 1 & $0.976^{* *}$ & $0.874 * *$ & 0.56 & $0.912 * *$ & $0.908 * *$ & -0.361 & $0.921 * *$ & $0.742 * *$ \\
\hline \multirow[t]{2}{*}{4} & $\mathbf{P}$ & & & & 1 & $0.877 * *$ & 0.655 & $0.908 * *$ & $0.839 * *$ & $-0.959 * *$ & $0.862 * *$ & $0.746 *$ \\
\hline & G & & & & 1 & $0.879 * *$ & 0.664 & $0.914 * *$ & $0.852 * *$ & -0.501 & $0.875^{* *}$ & $0.711 *$ \\
\hline \multirow[t]{2}{*}{5} & $\mathbf{P}$ & & & & & 1 & 0.621 & $0.99 * *$ & $0.778 * *$ & $-0.903 * *$ & $0.864 * *$ & $0.889 * *$ \\
\hline & $\mathbf{G}$ & & & & & 1 & 0.632 & $0.988 * *$ & $0.786^{* *}$ & -0.472 & $0.863 * *$ & $0.871 * *$ \\
\hline \multirow[t]{2}{*}{6} & $\mathbf{P}$ & & & & & & 1 & 0.651 & 0.433 & $-0.977 * *$ & 0.463 & 0.442 \\
\hline & $\mathbf{G}$ & & & & & & 1 & 0.661 & 0.453 & -0.492 & 0.482 & 0.435 \\
\hline \multirow[t]{2}{*}{7} & $\mathbf{P}$ & & & & & & & 1 & $0.805^{* *}$ & $-0.911 * *$ & $0.843 * *$ & $0.852 * *$ \\
\hline & $\mathbf{G}$ & & & & & & & 1 & $0.819 * *$ & -0.459 & $0.854^{* *}$ & $0.821 * *$ \\
\hline \multirow[t]{2}{*}{8} & $\mathbf{P}$ & & & & & & & & 1 & $-0.932 * *$ & $0.916^{* *}$ & $0.873 * *$ \\
\hline & $\mathbf{G}$ & & & & & & & & 1 & -0.435 & $0.923 * *$ & $0.833 * *$ \\
\hline \multirow[t]{2}{*}{9} & $\mathbf{P}$ & & & & & & & & & 1 & $-0.906 * *$ & $-0.955 * *$ \\
\hline & $\mathbf{G}$ & & & & & & & & & 1 & -0.381 & -0.515 \\
\hline \multirow[t]{2}{*}{10} & $\mathbf{P}$ & & & & & & & & & & 1 & $0.96 * *$ \\
\hline & $\mathbf{G}$ & & & & & & & & & & 1 & $0.904 * *$ \\
\hline 11 & & & & & & & & & & & & 1 \\
\hline \multicolumn{7}{|c|}{$\begin{array}{l}*, * * \text { - significant at } 5 \% \text { and } 1 \% \text { levels respectively } \\
1 \text { - Plant height at bulb formation stage } \\
2 \text { - Plant height at bulb filled stage } \\
3 \text { - Number of leaves at vegetative stage } \\
4 \text { - Number of leaves at bulb filled stage } \\
5 \text { - Neck thickness }\end{array}$} & \multicolumn{6}{|c|}{$\begin{array}{l}6 \text { - Neck diameter } \\
7 \text { - Polar diameter of bulb } \\
8 \text { - Equatorial diameter of bulb } \\
9 \text { - Days for harvesting } \\
10 \text { - Bulb weight } \\
11 \text { - Bulb yield per ha }\end{array}$} \\
\hline
\end{tabular}


Table 3 Path coefficient showing direct and indirect effects of different characters on bulb yield per of small onion during summer and Kuruvai season

\begin{tabular}{|c|c|c|c|c|c|c|c|c|c|c|c|c|}
\hline Characters & & 1 & 2 & 3 & 4 & 5 & 6 & 7 & 8 & 9 & 10 & 11 \\
\hline \multirow[t]{2}{*}{1} & $\mathbf{P}$ & 0.20052 & -0.10143 & 0.39857 & 0.33114 & 0.32012 & 0.0952 & $-0.9719 * *$ & 0.34566 & -0.28329 & $0.96075^{* *}$ & 0.584 \\
\hline & $\mathbf{G}$ & $0.853 * *$ & 0.644 & $-0.83 * *$ & -0.612 & $-0.966 * *$ & 0.027 & $0.926^{* *}$ & -0.405 & 0.514 & $0.977^{* *}$ & $0.891 * *$ \\
\hline \multirow[t]{2}{*}{2} & $\mathbf{P}$ & 0.13261 & -0.17753 & 0.31867 & 0.20571 & 0.52341 & 0.16511 & $-0.94004 * *$ & 0.42687 & -0.12103 & $0.8695 * *$ & $0.877 * *$ \\
\hline & G & 0.598 & $0.746 * *$ & $-0.764 * *$ & $-0.737 *$ & $-0.873 * *$ & 0.043 & $0.965 * *$ & -0.326 & 0.608 & $0.847 * *$ & 0.658 \\
\hline \multirow[t]{2}{*}{3} & $\mathbf{P}$ & 0.16527 & -0.09393 & 0.48358 & 0.29158 & 0.52258 & 0.10726 & $-0.97524 * *$ & 0.36541 & -0.20222 & $0.9821 * *$ & $0.804 * *$ \\
\hline & G & $0.801 * *$ & 0.699 & $-0.883 * *$ & -0.716 & $-0.936 * *$ & 0.035 & $0.955^{* *}$ & -0.395 & 0.557 & $0.917 * *$ & $0.8 * *$ \\
\hline \multirow[t]{2}{*}{4} & $\mathbf{P}$ & 0.17971 & -0.76914 & 0.38162 & 0.36948 & 0.05975 & 0.07714 & $-0.80375^{* *}$ & 0.33542 & -0.34679 & 0.09856 & 0.557 \\
\hline & $\mathbf{G}$ & $0.722 *$ & $0.748^{* *}$ & $-0.863 * *$ & $-0.734 *$ & $-0.888 * *$ & 0.041 & $0.917 * *$ & -0.365 & 0.523 & $0.945^{* *}$ & $0.734 *$ \\
\hline \multirow[t]{2}{*}{5} & $\mathbf{P}$ & 0.10368 & -0.14033 & 0.28837 & 0.15335 & 0.55331 & 0.16518 & $-0.85271 * *$ & 0.40574 & -0.03286 & $0.91579 * *$ & $0.895 * *$ \\
\hline & $\mathbf{G}$ & 0.693 & 0.649 & -0.693 & -0.521 & -0.153 & 0.039 & $0.935^{* *}$ & -0.338 & 0.431 & $0.948 * *$ & $0.883 * *$ \\
\hline \multirow[t]{2}{*}{6} & $\mathbf{P}$ & 0.11365 & -0.12343 & 0.30881 & 0.16969 & 0.51091 & 0.16797 & $-0.9552 * *$ & 0.41665 & -0.02378 & $0.98225^{* * *}$ & $0.861 * *$ \\
\hline & $\mathbf{G}$ & $0.802 * *$ & 0.518 & -0.048 & -0.136 & -0.338 & 0.062 & $0.934 * *$ & -0.188 & 0.422 & $0.815^{* *}$ & 0.44 \\
\hline \multirow[t]{2}{*}{7} & $\mathbf{P}$ & 0.16828 & -0.57925 & 0.40723 & 0.25643 & $0.88001 * *$ & 0.13854 & -0.09581 & 0.39214 & -0.09292 & $0.99473 * *$ & 0.697 \\
\hline & $\mathbf{G}$ & 0.688 & 0.663 & $-0.736 * *$ & -0.575 & -0.131 & 0.041 & $0.962 * *$ & -0.35 & 0.469 & $0.72 *$ & $0.841 * *$ \\
\hline \multirow[t]{2}{*}{8} & $\mathbf{P}$ & 0.15347 & -0.00333 & 0.39125 & 0.2744 & 0.29385 & 0.15496 & -0.09555 & 0.45163 & -0.17995 & $0.97918 * *$ & $0.897 * *$ \\
\hline & $\mathbf{G}$ & $0.727^{*}$ & 0.559 & -0.712 & -0.455 & -0.675 & 0.027 & $0.943 * *$ & -0.435 & 0.477 & $0.917 * *$ & $0.86 * *$ \\
\hline \multirow[t]{2}{*}{9} & $\mathbf{P}$ & -0.16282 & 0.10229 & -0.28029 & -0.36727 & -0.24047 & -0.01145 & 0.30845 & -0.23295 & 0.34888 & $-0.97687 * *$ & -0.271 \\
\hline & $\mathbf{G}$ & -0.656 & -0.268 & $0.926^{* *}$ & $0.93 * *$ & 0.589 & -0.073 & $-0.989 * *$ & 0.579 & -0.358 & $-0.735^{*}$ & -0.706 \\
\hline \multirow[t]{2}{*}{10} & $\mathbf{P}$ & 0.17462 & -0.01581 & 0.38353 & 0.27526 & 0.09477 & 0.14877 & -0.0357 & 0.43024 & -0.18721 & $0.94774 * *$ & $0.833 * *$ \\
\hline & $\mathbf{G}$ & $0.781 * *$ & 0.588 & $-0.726^{*}$ & -0.495 & $-0.861 * *$ & 0.029 & $0.945 * *$ & -0.398 & 0.468 & $0.828 * *$ & $0.94 * *$ \\
\hline
\end{tabular}

\section{Residual Effect $=$ Genotype $\boldsymbol{- 0 . 3 4 9 9}$; Phenotype $\boldsymbol{- 0 . 3 9 2 0}$}

1 - Plant height at bulb formation stage; 2 - Plant height at bulb filled stage; 3 - Number of leaves at vegetative stage; 4 - Number of leaves at bulb filled stage; 5 - Neck thickness; 6 - Neck diameter; 7 - Polar diameter of bulb; 8 - Equatorial diameter of bulb; 9 - Days for harvesting; 10 - Bulb weight; 11 - Bulb yield per ha 
This indicates the true relationships with bulb yield per hectare and direct selection for these traits would result in higher breeding efficiency for improving yield. Thus, these traits might be reckoned as the most important component traits of bulb yield per hectare. The indirect effect of traits was the cause of correlation and these factors are also to be considered simultaneously for selection of varieties.

\section{Acknowledgement}

The author is highly grateful to the Soil and Water Management Research Institute, Thanjavur for providing assistance for the conduct of research programme.

\section{References}

Aliya, U., M.D. Magaji, A.I. Yakubu and Dikko, A.U. 2007. Correlation and path coefficient analysis for some yield related traits in onion (Allium сера L.). Journal of Plant Science. 2 (3): 366-369.

Awale, D., A. Sentayehu and Getachew, T. 2011. Genetic variability and association of bulb yield and related traits in shallot (Allium cepa var. aggregatum Don.) in Ethiopia. Internat. J. Agric. Res., 6(7): 517-536

Barad, Y.M., K.B. Kathiria and Modha, K.G. 2012. Correlation and path coefficient studies in garlic (Allium sativum L.) over different environments. Veg. Sci., 39 (1): 79-82

Dewey, D.R. and Lu, K.H. 1959. A correlation and path coefficient analysis of components of crested wheat grass seed production. Agronomy Journal. 51: 515-618.

Dhall, R.K. and Brar, P.S. 2013. Genetic variability, correlation and path coefficient studies in garlic (Allium sativum) Veg. Sci., 40 (1): 102-104
Dhotre, M., T.B. Allolli, S.I. Athani and Halemani, L.C. 2010. Genetic variability, character association and path analysis studies in Kharif onion (Allium cepa var. cepa L.). Asian J. Hort., 5(1): 143 - 146

Hayder, A., N. Sharker, M.B. Ahmed, M.M. Hannan, M.A. Razvy, M. Hussain, A. Hoques and Karim, R. 2007. Genetic variability and interrelationship in onion (Allium cepa L.) Middle East J. Sci. Res., 2 (3\&4): 132-134

Hosamani, R.M., B.C. Patil and Ajjappalavara, P.S. 2010. Genetic variability and character association studies in onion (Allium cepa L.). Karnataka J. Agric. Sci., 23(2): $302-$ 305.

Ijoyah, M.O., Rakotomavo, H. and Naiken, M.V. 2008. Yield performance of four onion (Allium Cepa L.) varieties compared with the local variety under open field conditions at Anse Boileau, Seychelles. Journal of Science and Technology. 28(3): 28-33.

Jilani, M.S. and Ghafoor, A. 2003. Screening of local onion varieties for bulb formation. International Journal of Agriculture and Biology. 5 (2): 129133

Johnson, H.W., H.F. Robinson and Comstock, R.E. 1955. Genotypic and phenotypic correlations in soybeans and their implications in selection. Agronomy Journal. 47: 477-482.

Kimani, P.M., Kariuki, J.W., Peters, R. and Rabinowitch, H.D. 1993. Influence of the environment on the performance of some onion cultivars in Kenya. African Crop Science Journal. 1(1): 15-23.

Raghuwanshi, O.S., P.K. Jain, S.K. Sengupta, A.S. Dangi, N.R. Verma and Sunil Prajapati. 2016. Correlation and path analysis study in diverse onion (Allium cepa L.) genotypes. The Asian Journal 
of Horticulture. 11(1): 19-24

Saini, M.S. and Maurya, I.B. 2014. Character association and path coefficient analysis in Kharif onion (Allium cepa L.) Internat. J. Adv. Res., 2(6): 692 696.

Sharma, A., S. Chandrakar and Thakur, D. K. 2015. Character association and path co-efficient analysis in kharif onion (Allium cepa L.) genotypes. Internat. J. Plant Sci., 10(1): 70-73.

Som Pal Baliyan. 2014. Evaluation of onion varieties for productivity performance in Botswana. World Journal of Agricultural Research. 2(3): 129-135

\section{How to cite this article:}

Visalakshi, M., C. Porpavai and Pandiyan, M. 2018. Correlation and Path Coefficient Analysis of Yield and Yield Associated Traits in Small Onion Int.J.Curr.Microbiol.App.Sci. 7(07): 3065-3072. doi: https://doi.org/10.20546/ijcmas.2018.707.357 